\title{
Hydrogen production from aqueous glycerol using titanate nanotubes decorated with Au nanoparticles as photocatalysts
}

\author{
THALLES M.F. MARQUES ${ }^{1}$, REINALDO N. MORAIS ${ }^{2}$, FRANCISCO X. NOBRE ${ }^{3}$, JARDEL M. \\ ROCHA $^{2}$, ANUPAMA GHOSH ${ }^{5}$, THIAGO ANDRÉ S. SOARES ${ }^{4}$, BARTOLOMEU C. VIANA ${ }^{5,6}$, \\ GIOVANNA MACHADO ${ }^{4}$, JEAN CLAUDIO S. COSTA ${ }^{2}$ and JOSÉ M.E. DE MATOS ${ }^{2}$
}

\author{
${ }^{1}$ Instituto Federal de Educação, Ciência e Tecnologia do Piauí, Campus São João do Piauí, \\ Travessa Sete de Setembro, s/n, Centro, São João do Piauí, Piauí, 64760-000, Brazil. \\ ${ }^{2}$ Departamento de Química, Universidade Federal do Piauí, Avenida Universitária, s/n, Ininga, 64049-550 Teresina, PI, Brazil \\ ${ }^{3}$ Instituto Federal de Educação, Ciência e Tecnologia do Amazonas, Campus Coari, \\ Estrada Coari Itapeua, s/n, Itamarati, 69460-000 Coaro, AM, Brazil \\ ${ }^{4}$ Centro de Tecnologias Estratégicas do Nordeste, Av. Prof. Luís Freire, 1, Cidade Universitária, 50740-545 Recife, PE, Brazil \\ ${ }^{5}$ Departamento de Física Universidade Federal do Piauí, Avenida Universitária, Ininga, s/n, 64049-550 Teresina, PI, Brazil \\ ${ }^{6}$ Laboratório Interdisciplinar de Materiais Avançados/LIMAV, Programa de Pós Graduação em Ciência e Engenharia \\ dos Materiais, Universidade Federal do Piauí, Avenida Universitária, Ininga, s/n, 64049-550 Teresina, PI, Brazil
}

Manuscript received on January 24, 2019; accepted for publication on April 11, 2019

\begin{abstract}
How to cite: MARQUES TMF, MORAIS RN, NOBRE FX, ROCHA JM, GHOSH A, SOARES TAS, VIANA BC, MACHADO G, COSTA JCS AND MATOS JME. 2019. Hydrogen production from aqueous glycerol using titanate nanotubes decorated with Au nanoparticles as photocatalysts. An Acad Bras Cienc 91: e20190082. DOI 10.1590/0001-3765201920190082.
\end{abstract}

\begin{abstract}
Protonated titanate nanotubes (HTiNts) were synthesized using the hydrothermal method, followed by proton exchange with acid. Gold nanoparticles decorated titanate nanotubes (AuHTiNts) were obtained by the reduction of $\mathrm{AuCl}_{4}^{-}$under vigorous stirring with an aqueous solution of HTiNts containing $1 \mathrm{wt} \%$ of ascorbic acid. To investigate the surface structural chemistry of the titanate and AuHTiNts, the following characterization methods were used: scanning and transmission electron microscopy, X-ray diffraction, UV-Vis diffuse reflectance spectroscopy, Raman spectroscopy and X-ray photo-electron spectroscopy. The mean internal and external diameters for titanate nanotubes were found to be $5.46 \pm 0.08$ $\mathrm{nm}$ and $8.42 \pm 0.03 \mathrm{~nm}$, respectively, whereas the mean diameter of gold nanoparticles was measured to be $9.68 \mathrm{~nm} \pm 0.03 \mathrm{~nm}$. The as-synthesized AuHTiNts was used as photocatalyst in hydrogen production from glycerol as a sacrificial agent. The enhancement in the production of hydrogen, using the heterogeneous AuHTiNts catalysts, can be attributed to the intrinsic catalytic potential of gold as well as its interactions with titanate nanostructure.
\end{abstract}

Key words: Titanate nanotubes, Au nanoparticles, catalytic hydrogen production, glycerol.

\footnotetext{
Correspondence to: José Milton Elias de Matos

E-mail: jmematos@ufpi.edu.br

ORCid: https://orcid.org/0000-0003-3476-399X

Thalles Moura Fé Marques

E-mail: marquesttt@gmail.com

ORCid: https://orcid.org/0000-0002-5211-5235
} 


\section{INTRODUCTION}

After Fujishima and Honda (1972) reported the water oxidation with $\mathrm{TiO}_{2}$ as the photo-catalyst for the first time in 1972, generating hydrogen and oxygen, many studies have been developed with different electrolytes (De la Piscina and Homs 2008) and photoelectrodes (Valdes et al. 2012) to increase the hydrogen production (Ahmad et al. 2015). However, the $\mathrm{H}_{2}$ production from the water splitting is too low to meet the industrial demand (Crabtree et al. 2004). On the other hand, the photocatalytic process of organics with semiconductors has proved to be an efficient and attractive method to produce hydrogen with the aid of solar energy through a clean, sustainable and renewable route (Estahbanati et al. 2017). Glycerol, a by-product of the biodiesel production (McNutt and Yang 2017), has a great potential as a starting material for sustainable hydrogen production (Bowker et al. 2009).

Titanium oxide is one of the most used photocatalysts owing to their exceptional electronic and optical properties, high oxidation power, low-toxicity, chemical stability, abundance and low cost of synthesis (Fang et al. 2017). Titanate nanotubes (TiNts) have mesoporous morphology and high specific surface area (Ge et al. 2016), with photocatalytic properties similar to $\mathrm{TiO}_{2}$ (Guimarães et al. 2017), which is even better for photocatalysis and therefore, has received much attention in recent years (Abdullah and Kamarudin 2017, Ge et al. 2017). Still, the usage of TiNts, as well as $\mathrm{TiO}_{2}$ as efficient photocatyst is limited due to their high band gap $(3.4 \mathrm{eV})$ which restricts their capability to capture light beyond the UV region (Liu et al. 2014). To overcome this barrier, many studies has been focused on the synthesis of suitable hetero-nanostructures based on TiNT and $\mathrm{TiO}_{2}$ nanotubes as substrates which can be decorated with different active catalysts leading to photocatalytic applications (Kukovecz et al. 2016, Yang et al. 2015).

Catalytic hydrogen production from photoreforming of glycerol-water mixture using titanate and related nanostructures had been a great area of interest although its mechanistic insights are yet to be fully understood. Upon irradiation of photons, having higher energy than the band gap of titanate or related nanostructure, the electrons (e-) are excited from valence band to conduction band, leaving behind holes $\left(\mathrm{h}^{+}\right)$. These photogenerated $\mathrm{e}^{-/}$ $\mathrm{h}^{+}$pair react with available oxi-reducible species, such as surface bond water molecules or dissolved oxygen molecules which further react following many possible oxi-reduction routes, evolving different reactive oxygen species (ROS), such as $\mathrm{O}_{2}^{--},{ }^{1} \mathrm{O}_{2}, \mathrm{H}_{2} \mathrm{O}_{2}$ and $\mathrm{OH}^{\cdot}$ etc (Jedsukontorn et al. 2018). These ROS react with glycerol molecules in many possible ways leading to its complete oxidation to $\mathrm{CO}_{2}$ via generation of many organic intermediates with general formulae etc $\mathrm{C}_{\mathrm{x}} \mathrm{H}_{\mathrm{y}} \mathrm{O}_{\mathrm{z}}$, such as glyceraldehyde $\left(\mathrm{C}_{3} \mathrm{H}_{6} \mathrm{O}_{3}\right)$, dihydroxyacetone $\left(\mathrm{C}_{3} \mathrm{H}_{6} \mathrm{O}_{3}\right)$, glycolaldehyde $\left(\mathrm{C}_{2} \mathrm{H}_{4} \mathrm{O}_{2}\right)$, acetaldehyde $\left(\mathrm{C}_{2} \mathrm{H}_{4} \mathrm{O}\right)$, formaldehyde $\left(\mathrm{CH}_{2} \mathrm{O}\right)$ and formic acid $\left(\mathrm{CH}_{2} \mathrm{O}_{2}\right)$ in the liquid phase (Sanwald et al. 2016). Careful study with $\mathrm{D}_{2} \mathrm{O}$ showed that both $\mathrm{H}_{2} \mathrm{O}$ and glycerol molecule takes part in the generation of the $\mathrm{H}_{2}$ (Fujita et al. 2016) and the total oxi-reduction reaction can be written as (Daskalaki et al. 2009):

$\mathrm{C}_{3} \mathrm{H}_{8} \mathrm{O}_{3}+3 \mathrm{H}_{2} \mathrm{O} \stackrel{\text { hv }>\mathrm{BG}}{\longrightarrow} 3 \mathrm{CO}_{2}+7 \mathrm{H}_{2}$ Whereas the half reaction can be written as Anode: $\mathrm{C}_{3} \mathrm{H}_{8} \mathrm{O}_{3}+14 \mathrm{~h}^{+}+3 \mathrm{H}_{2} \mathrm{O} \longrightarrow 3 \mathrm{CO}_{2}+14 \mathrm{H}^{+}$ Cathode: $14 \mathrm{H}^{+}+14 \mathrm{e}^{-} \longrightarrow 7 \mathrm{H}_{2}$

The noble metals, e.g. Au, Pt and Pd have been reported as efficient dopants for activation in visible light, thus improving the performance of the photocatalysts (Bamwenda et al. 1995, Jakob et al. 2003, John et al. 1983, Sakthivel et al. 2004). The Fermi levels of these noble metals are smaller than those of semiconductors, such 
as $\mathrm{TiO}_{2}$ and TiNts, which results in an effective transfer of photogenerated electrons from the semiconductor conduction band to the metal particles (Etacheri et al. 2015). This electron capture process significantly reduces the electronhole recombination rate, giving rise to more efficient photocatalytic reactions. Among other advantages, gold nanoparticles (AuNPs) allow the photosensitization of the heterostructure due to the possibility of the surface plasmonic resonance effect (SPR) (Cushing et al. 2015, Primo et al. 2011). Also it reduces the energy required to promote the formation of the electron-hole pairs (Ingram et al. 2011, Primo et al. 2011, Rouby et al. 2017). In addition, Pusztai et al. reported that the band gaps of pure titanate nanowires $(3.10 \mathrm{eV})$ and nanotubes $(3.07 \mathrm{eV})$ reduce to $2,84 \mathrm{eV}$ at $1 \%$ and $2,74 \mathrm{eV}$ at 2,5\% Au doping respectively (Pusztai et al. 2014).

Murdoch et al. reported that AuNPs in the range of 3-30 nm on the surface of $\mathrm{TiO}_{2}$ are very active in the production of hydrogen from ethanol (Murdoch et al. 2011). Similar improvement in photocatalytic properties had been observed in the cases of $\mathrm{ZnO}$ crystals (Wang et al. 2016), heterogeneous Au-BiVO nanostructures (Cao et al. 2011) and TiNts (Dosado et al. 2015) upon AuNPs decoration on the surface of these nanostructures. The surface plasmon resonance effect (SPR) allows direct electron transport directly from the metal to the conducting band of the semiconductor (Primo et al. 2011, Rouby et al. 2017) and improve the photocatalytic activity (Murdoch et al. 2011).

Well-dispersed AuNPs have been used to decorate TiNts in order to increase the efficiency of photocatalytic reactions in general and photocatalytic $\mathrm{H}_{2}$ production, in particular. The reasons for this synergetic effect observed are: the strong absorption ability of AuNPs, owing to the SPR effect that improves the visible light response, and the fast electron transfer from TiNts to AuNPs, which traps the photogenerated electrons and prevent their recombination with holes (Yang et al. 2015). Renhong Li et al. reported that redistribution of surface charge between AuNPs and protonated titanate nanotubes (HTiNts) leads to a high catalytic activity for photocatalytic hydrogen generation from the dehydrogenation of formic acid without any additive ( $\mathrm{Li}$ et al. 2016). In the attempt of developing more efficient catalysts for water splitting reactions the use of organic capping ligands for AuNPs synthesis lowers the catalyst effectiveness because a part of this organic reagent remains at the interface of the metal and the nanotubes, leading to a poor Schottky barrier between Au and TiNts (Li et al. 2012). Therefore, it is of extreme necessity to develop direct nanoparticle decoration methods without organic moiety on to the hosting nanomaterial surface.

Herein we report an organic capping-agent free method of AuNPs decoration on to the surface of TiNTs after proton exchange to generate gold nanoparticle decorated protonated TiNts (AuHTiNts) which has been used as a photocatalyst for photogeneration of $\mathrm{H}_{2}$ using glycerol as a sacrificial agent. By AuNPs decoration, we have been able to overcome the problem of large band gap of TiNts, a central issue that restricts the optical response in only UV range and thereby lowers the photocatalytic performance of these semiconductors and had been able to extend the application of this material in the wider visible range.

\section{EXPERIMENTAL PROCEDURES}

$\mathrm{TiO}_{2}$-Anatase $(\geq 99.8 \%), \mathrm{HAuCl}_{4} \cdot 3 \mathrm{H}_{2} \mathrm{O}(99 \%)$ and glycerol ( $\geq 99 \%$ ) were purchased from SigmaAldrich and used without further purification. $\mathrm{HCl}$ (36.5-38 wt.\%) and $\mathrm{NaOH}$ (98\%) were purchased from Dinâmica, ethylene glycol and ascorbic acid were purchased from Vetec, and also were used without further purification. All solutions were prepared using deionized water. 


\section{TITANATE NANOTUBES PREPARATION}

Titanate nanotubes were prepared using commercial $\mathrm{TiO}_{2}$ (anatase) (purity 99.8\%). Typically, $3.0 \mathrm{~g}$ of $\mathrm{TiO}_{2}$ were mixed in $90 \mathrm{~mL}$ of a $10 \mathrm{~mol} \mathrm{~L}^{-1} \mathrm{NaOH}$ solution, stirred for 30 minutes in a magnetic stirrer to obtain a homogeneous dispersion, then transferred to a Teflon reactor and taken to a microwave oven (Panasonic - $2.45 \mathrm{MHz}$, maximum power of $700 \mathrm{~W}$ ) and heated at $150{ }^{\circ} \mathrm{C}$ for $4 \mathrm{~h}$. After cooling the system to room temperature, a portion of the resulting white solid was washed with deionized water to $\mathrm{pH} 10$ in order to generate Sodium titanate nanotubes (NaTiNts) and the other part with $0.1 \mathrm{~mol} \mathrm{~L}^{-1}$ aqueous $\mathrm{HCl}$ solution to $\mathrm{pH}$ 6 to generate proton exchanged titanate nanotubes (HTiNts). Both the samples were vacuum dried for $12 \mathrm{~h}$ (Ferreira et al. 2006).

SYNTHESIS OF AU NANOPARTICLES SUPPORTED ON TITANATE NANOTUBES

To generated AuHTiNts, HTiNts were added to an aqueous solution $(60 \mathrm{~mL})$ containing $1 \mathrm{wt} \%$ of ascorbic acid (AA) under vigorous stirring. Then, $150 \mu \mathrm{L}$ of a $1 \% \mathrm{AuCl}_{4(\text { aq })}^{-}$solution was added and this mixture was heated to $110{ }^{\circ} \mathrm{C}$ and kept on stirring for $2 \mathrm{~h}$.

\section{CHARACTERIZATIONS}

Raman spectroscopy experiments were performed in a confocal Raman spectrometer, Bruker Senterra, with objective lenses of 50x and $785 \mathrm{~nm}$ laser excitation source. The low laser power density was used to prevent the sample from overheating. A spectral resolution of $3 \mathrm{~cm}^{-1}$ was used and the interval used was $80-1050 \mathrm{~cm}^{-1}$.

The powder X-ray diffraction (XRD) patterns were obtained with a Shimadzu XRD6000 diffractometer using $\mathrm{Cu} \mathrm{K} \alpha$ radiation $(\lambda=1.5406$ $\AA$ ) operating at $30 \mathrm{~mA}$ and $40 \mathrm{kV}$. A sweep rate of $2^{\circ} \mathrm{min}^{-1}$ was used and the range of $2 \theta$ was 5-70 degrees.
The transmission electron microscopy (TEM) images were obtained using a JEOL -JEM-2010F microscope operating at $200 \mathrm{keV}$. The samples were prepared by dropping an aqueous suspension of powdered sample on to a holey carbon-coated copper grid (300 mesh, SPI supplies) and letting the water evaporate at ambient temperature, during $24 \mathrm{~h}$. Catalyst compositional were acquired by XEDS spectrum imaging (XEDS-SI), ThermoNoran XEDS.

The scanning electron micrographs (SEM) were collected using a field emission scanning electron microscope, FEI Quanta FEG250. The elemental analysis by X-ray energy dispersion spectroscopy (EDX) was performed using a EDX probe EDAX Apollo X, attached to FESEM. The powdered samples were adhered on to a carbon tape and placed on to the SEM sample holder.

The X-ray photoelectron spectra (XPS) were obtained with a Scienta Omicron ESCA+ spectrometer system equipped with an EA 125 hemispherical analyzer and an Xm 1000 monochromatic X-ray source (A1 K $\alpha, 1486.7 \mathrm{eV}$ ). The X-ray source was used with a power of 280 $\mathrm{W}$ as the spectrometer worked in a constant-pass energy mode of $50 \mathrm{eV}$. A Scienta Omicron CN10 charge neutralizer with a beam energy of $1.6 \mathrm{eV}$ charge was used to compensate the charge effect while the spectra were obtained. For corrections of peak shifts due to the remaining charge effect, the binding energies of all spectra were scaled with use of the main peak of C $1 \mathrm{~s}$ at $284.8 \mathrm{eV}$ as a reference. Wide-scan spectra, for peak identification, were recorded with a step of $0.5 \mathrm{eV}$, and high-resolution spectra for core levels were obtained with the step of $0.03 \mathrm{eV}$. All the X-ray photoelectron spectra were analyzed with the software program CasaXPS, where the background in high-resolution spectra is computed by the Shirley method. Peak fitting of core levels was done with an asymmetric GaussianLorentzian product function for the peak shape. 
The UV-Vis diffuse reflectance spectra were obtained by a UV-Vis spectrophotometer (Agilent, Cary 300) equipped with an accessory for diffuse reflectance sampling using $\mathrm{BaSO}_{4}$ as reference material. $2 \mathrm{~g}$ of $\mathrm{BaSO}_{4}$ and $50 \mathrm{mg}$ of titanate material were mixed well and pressed in the form of pellets.

\section{CATALYSIS}

Photo-assisted hydrogen generation experiments were carried out in a calibrated $35-\mathrm{mL}$ gasenclosed photochemical double quartz reactor in which water circulates as an infrared filter and controls the solution temperature $\left(25^{\circ} \mathrm{C}\right)$ under continuous magnetic stirring. AuHTiNts (7,5 mg)

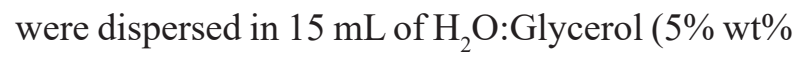
Glycerol) solution and introduced into the reactor. Prior to the irradiation, the system was de-aerated using Ar-vacuum cycles for about 10 min to reduce the oxygen content.

The system was illuminated by a $600 \mathrm{~W}$ solar simulator (Newport, Power solar) and a 450W Xe lamp (Ushio) at one sun intensity. The light intensity incident on the cell was measured with a calibrated Si photodiode. The evolution of $\mathrm{H}_{2}$ production was monitored by collecting $500 \mu \mathrm{L}$ aliquots of the gas, in duplicates, at intervals of $0.5 \mathrm{~h}$ (Sample Lock Syring, Hamilton). The amount of accumulated $\mathrm{H}_{2}$ produced in the headspace of sealed quartz reactor was measured using an Agilent gas chromatography equipment with a TCD detector and HP-PLOT/Q $30 \mathrm{M}$, HPMOLESIEVE $30 \mathrm{M}$ columns. For rate determination, data were taken at regular intervals from $30 \mathrm{~min}$ to $210 \mathrm{~min}$.

Hydrogen evolution was observed under one sun condition as a function of time. The experiment was performed in a 5-cycle sequence without replacing the glycerol solution (Figure 8). In the first cycle, (named cycle-1 in the Fig 8) after $1 \mathrm{~h}$ light exposure, irradiation was intentionally interrupted for a period of $1 \mathrm{~h}$. This procedure was repeated twice to observe in the sample behavior in the dark. In the other four, much longer cycles (named cycle-2, 3, 4 and 5 in the Fig 8), the sample was irradiated for 5 hours and the $\mathrm{H}_{2}$ evolution was measured constantly in each 30 minutes. After 5 hours, the irradiation was stopped and the reactor was left closed in a darkroom for $18 \mathrm{~h}$. After each cycle, the system was fully evacuated, purged repeatedly and the irradiation was restarted for a new cycle.

\section{RESULTS AND DISCUSSION}

The Raman spectra of NaTiNts, HTiNts and AuHTiNts are illustrated in Fig. 1a. According to previous studies (Ferreira et al. 2006, Marques et al. 2015), the vibrational modes centered at around 164 and $195 \mathrm{~cm}^{-1}$ are attributed to the lattice modes $\left(\mathrm{Na}^{+}-\mathrm{O}-\mathrm{Ti}\right)$; modes centered at 275, 448 and 662 and $700 \mathrm{~cm}^{-1}$ correspond to Ti-O-Ti stretching from the edge-sharing $\mathrm{TiO}_{6}$ octahedron and the mode at $906 \mathrm{~cm}^{-1}$ represent the stretching of unshared Ti-O bonds in the units of distorted $\mathrm{TiO}_{6}$ of NaTiNts (Viana et al. 2011). In the HTiNts spectrum, it was observed that the highest $\left(906 \mathrm{~cm}^{-1}\right)$ and the lowest ( 145 and $195 \mathrm{~cm}^{-1}$ ) energy modes have their wave numbers and intensities widely affected by the proton ion. The most affected band is the one related to Ti-O bond whose oxygen is not shared among the $\mathrm{TiO}_{6}$ units, the mode around $906 \mathrm{~cm}^{-}$ ${ }^{1}$, which disappears after the protonation reaction (Viana et al. 2011). Comparing the Raman spectra of AuTiNts with those of HTiNts, it was observed that they have the same Raman spectral characteristics of intermediary energy, indicating that the $\mathrm{TiO}_{6}$ octahedron network of TiNts did not suffer major changes after $\mathrm{Au}$ decoration. In addition, one of the important aspects to be highlighted is the emergence of new bands centered at 142, 393, 515 and $639 \mathrm{~cm}^{-1}$, which can be related to $\mathrm{E}_{\mathrm{g}}, \mathrm{B}_{1 \mathrm{~g}}$, $\mathrm{A}_{1 \mathrm{~g}}$ and $\mathrm{E}_{\mathrm{g}}$ modes of anatase phase respectively. This phase transformation from TiNT to anatase 
may be attributed to the similar topochemical reaction reported in the earlier literature where transitions of titanate nanostructures to $\mathrm{TiO}_{2}$ (anatase) nanoparticles had been observed in acidic aqueous dispersions at temperatures close to room temperature (Zhu et al. 2005).

The X-ray diffraction patterns (XRD) provided information about the crystalline structure and the interlamellar distances of NaTiNts and HTiNts, as well can characterize the crystalline nature of decorated AuNPs. The X-ray diffraction data (Fig. 1b) indicate that the crystalline structure and tubular morphology of HTiNts (Dzubiella 2010) were preserved after being decorated with AuNPs. The slight changes in the diffractogram profiles of NaTiNts to HTiNts are in accordance with those reported in the literature (Ferreira et al. 2006). It highlights four typical broad diffraction peaks of NaTiNts: i) around $10^{\circ}(2 \theta)$, referring to the interlamellar distance (Marques et al. 2017); ii) $24^{\circ}(2 \theta)$, referring to the diagonal plans formed by ion-lamella (Morgado et al. 2011); (iii) $28^{\circ}$ $(2 \theta)$, referring to the diagonal plans formed by lamellar sodium-interaction (Morgado et al. 2006); and (iv) $48^{\circ}(2 \theta)$, referring to the plans formed by the $\mathrm{TiO}_{6}$ network (Bavykin et al. 2006, Chen et al. 2002). These peaks are consistent with the crystallographic information file reported for the phase $\mathrm{Na}_{2} \mathrm{Ti}_{3} \mathrm{O}_{7} \cdot \mathrm{nH}_{2} \mathrm{O}$ (JCPDS \#. 13-3129), indexed to the planes (200), (110), (211) and (020), respectively (Ferreira et al. 2006). In the diffractogram profile of HTiNts, it was observed that the intensity of the peak centered at $2 \theta=28$ - decreases compared to the peak located in the same region of the NaTiNts sample, suggesting the exchange of $\mathrm{Na}^{+}$ions with $\mathrm{H}^{+}$ions (Morgado et al. 2006), corroborating with the Raman results. The reduction and AuNPs decoration processes on the surface of HTiNts affected the intensity of some crystalline planes of nanotubes, but the overall tubular structure was preserved for the AuHTiNts. The XRD peak at around $10^{\circ}$, corresponding to the plane (200), related to the interlamellar distance, as well the diagonals planes of the nanotubes structure, represented by the peaks between $20^{\circ}$ and $40^{\circ}$, exhibited changes in the intensity reflecting the insertion of $\mathrm{H}^{+}$and $\mathrm{Au}^{+}$ions from the $\mathrm{Au}^{+}$exchange reaction in an acid medium, leading to AuNPs decoration. The insertion of $\mathrm{Au}^{+}$with the removal of $\mathrm{H}^{+}$and $\mathrm{Na}^{+}$, remaining after the protonation process, resulted in the distortion of these crystalline planes, reducing the intensity of the peaks at $10^{\circ}$ and $28^{\circ}$ (20) along with a peak dislocation at $10^{\circ}(2 \theta)$ to lower values, thereby suggesting the increase of the interlamellar distance through the insertion of $\mathrm{Au}^{+}$ ions between the lamellas of the nanotubes (Viana et al. 2011).

The AuNPs formation was confirmed by indexing the peaks at $38^{\circ}$ and $44^{\circ}$ with the crystallographic data from the Card JCPDS $n^{\circ}$ 65-2870, pertinent to the Bragg (111) and (200) reflection pattern for a cubic face-centered phase (CFC) of $\mathrm{Au}$. The average size of the AuNPs was estimated applying the Scherrer equation on fullwidth at the half maxima of the most of intense reflection (111), which was calculated to be around $9.9 \mathrm{~nm}$ of size. Also a diffraction peak at $25^{\circ}$ was observed which was indexed as (101) plane reflection of the $\mathrm{TiO}_{2}$ anatase phase (JCPDS Card. $\mathrm{n}^{\mathrm{o}}$ 21-1272), confirming, the presence of some anatase phase, suggesting occurrence of some TiNT-anatase phase transformation due to the topochemical reaction in the acidic medium, also observed by Zhu et al (2005), corroborating with the findings of Raman spectroscopy.

The TEM images for HTiNts and AuHTiNts were obtained with the purpose to confirm the nanomorphology and to measure the average value of the outer $\left(<\mathrm{d}_{\text {ext }}>\right)$ and inner diameter $\left(<\mathrm{d}_{\mathrm{int}}>\right)$ of the nanotubes, as well as the interplanar distance and diameter of AuNPs (Fig. 2). The TEM images of HTiNts confirms the retention of tubular morphology with an open-ended, rolledup structure (Fig. 2a, b), very characteristic of 

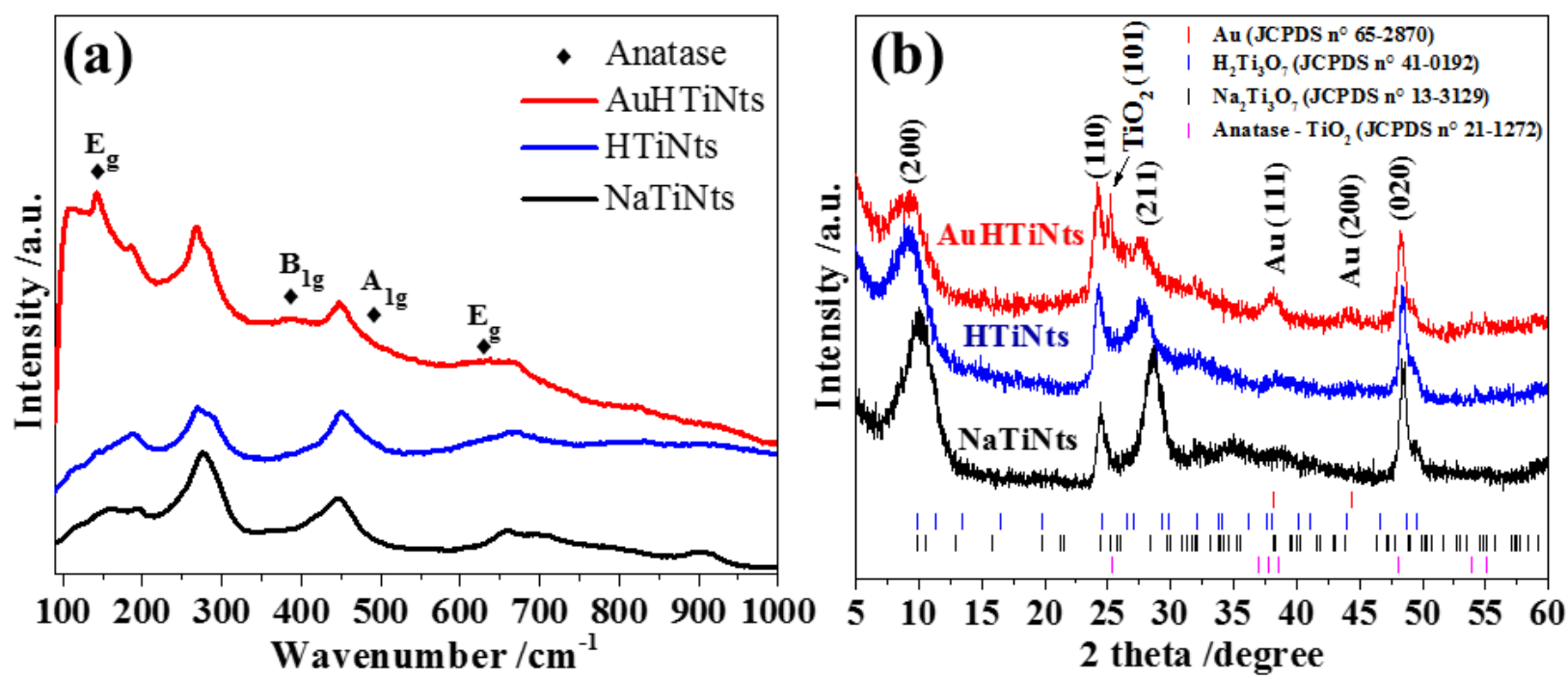

Figure 1 - (a) Raman spectra of NaTiNts, HTiNts and AuHTiNts, (b) XRD pattern of NaTiNts, HTiNts and AuHTiNts.

the titanate nanotubes in general with a nonhomogeneous distribution of the length and width (Tang et al. 2013, Vempati et al. 2015). The inner and outer diameter of nanotubes were measured from the images (Fig. 2c, d) and the average for the external diameter distribution $\left(<\mathrm{d}_{\text {ext }}>\right)$ and that for the inner diameter distribution $\left(<\mathrm{d}_{\text {int }}>\right.$ ) were found to be $8.42 \pm 0.03 \mathrm{~nm}$ and $5.46 \pm 0.08 \mathrm{~nm}$, respectively. The interplanar distance was measured for HTiNts to be $0.69 \mathrm{~nm}$. Both the average inner and outer diameters as well as the interplanar distance are in good agreement with those reported in the literature (Ferreira et al. 2006).

The AuNPs formation and interaction on the HTiNts surface resulted in the anchoring of the gold nanoparticles on to the surface of the nanotubes (Fig. 3a, b and d). The distribution of the AuNPs average size $\left(<\mathrm{d}_{\mathrm{Au}}>\right)$ was determined from the TEM images (Fig. 3a) and found to be $9.68 \pm 0.03$ $\mathrm{nm}$ (Fig. 2c), agreeing with the value obtained by XRD measurements, as shown above. The AuNPs morphology and size obtained in the present study are in good agreement with the results presented in the literature ( $\mathrm{Li}$ et al. 2016). AuHTiNts were subjected to X-ray energy dispersive spectroscopy by TEM (EDS-TEM). The measurement was performed at the indicated region (indicated as "1" in Fig. 3d) between two AuNPs particles (Fig. 3d) to confirm the elemental composition to be pure $\mathrm{Au}$ (Fig. 3e), the signal of $\mathrm{Cu}$ coming from the TEM grid.

The elemental composition of NaTiNts, HTiNts and AuHTiNts samples was investigated by EDS. The atomic ratio of $\mathrm{Na} / \mathrm{Ti}$ was found to be 0.71 and 0.05 for NaTiNts and HTiNts, respectively. The amount of $\mathrm{Na}^{+}$ions in NaTiNts is in accordance with the chemical formula $\mathrm{Na}_{2}$ ${ }_{x} \mathrm{H}_{\mathrm{x}} \mathrm{Ti}_{3} \mathrm{O}_{7} \cdot \mathrm{nH}_{2} \mathrm{O}(0 \leq \mathrm{x} \leq 2)$ (Ferreira et al. 2006, Marques et al. 2017). After washing with $\mathrm{HCl}$, the sodium content decreased drastically (about 90\%) in the HTiNts (Morgado et al. 2006), suggesting that ion exchange by $\mathrm{H}^{+}$to $\mathrm{Na}^{+}$has occurred successfully. Also the presence of Au has been verified in the AuHTiNts sample, a more detailed study of the chemical environment was performed by X-ray photoelectron spectroscopy (XPS), Fig. 4.

The electronic structure and the surface composition of titanate nanotubes (NaTiNts, HTiNts and AuHTiNts) were studied by XPS. The maximum energy for $\mathrm{C} 1 \mathrm{~s}(284.8 \mathrm{eV})$ was used as a reference of binding energy. The detailed spectra of all the TiNT nanotubes are shown in Fig. 4. The 


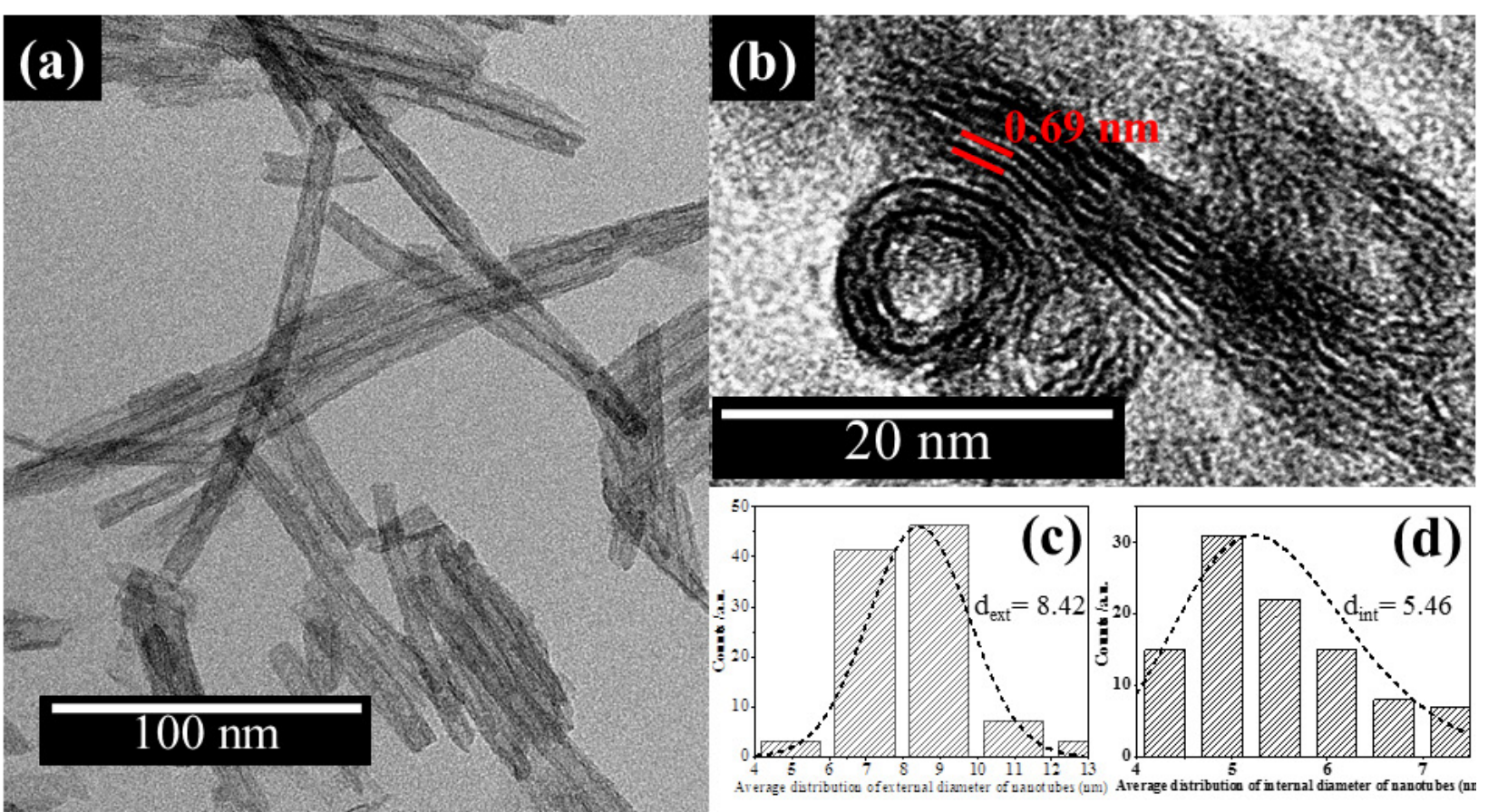

Figure 2 - TEM images of HTiNts (a, b) and distribution of the external (c) and internal (d) diameter for HTiNts.
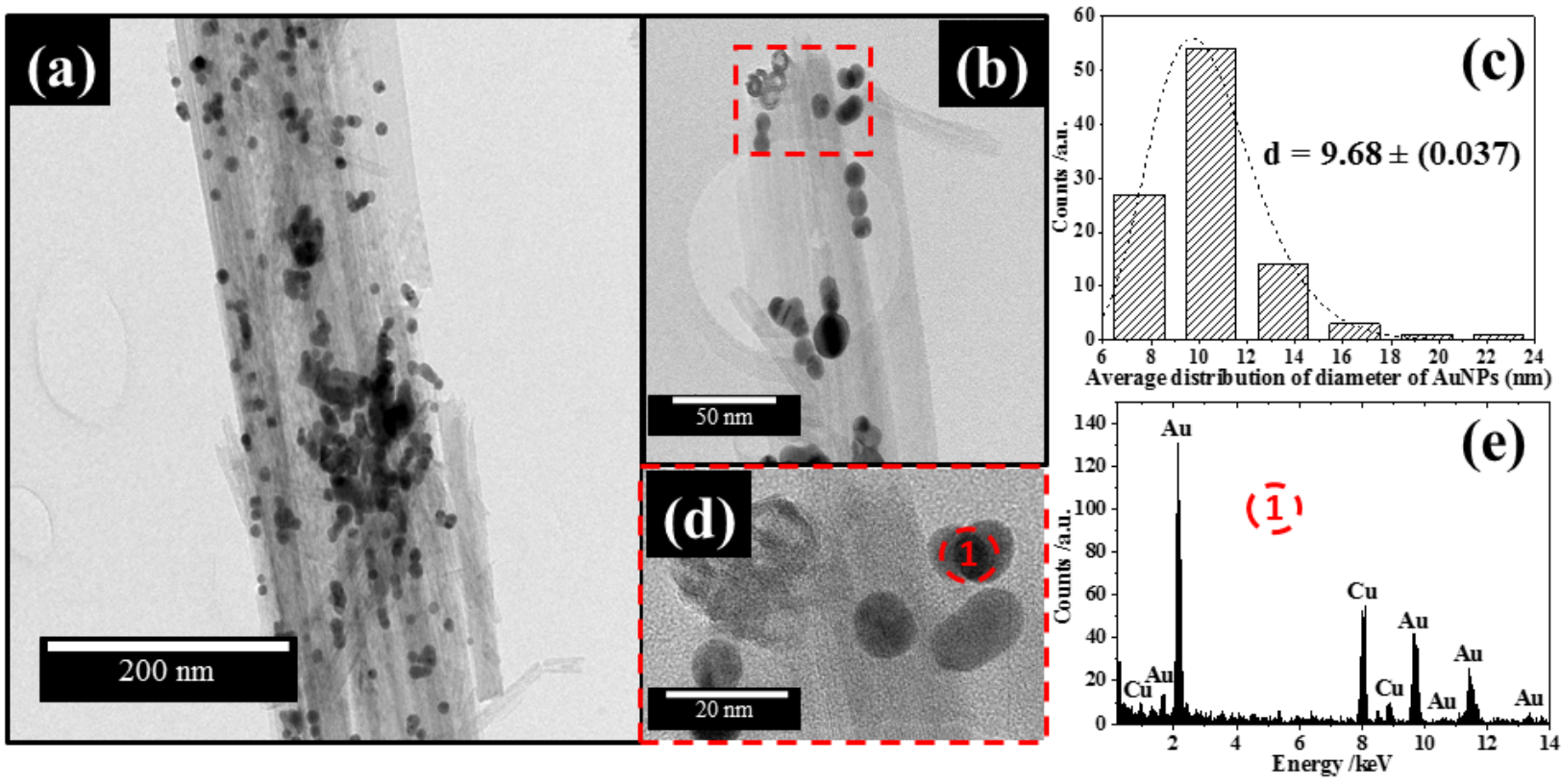

Figure 3 - TEM images of AuHTiNts (a, b and $\mathbf{d})$ and distribution of diameter of AuNPs (c) and X-ray spectroscopy of energy dispersion (e).

Ti 2p signals for NaTiNts, HTiNts and AuHTiNts were shown in Fig. 4a. The spectral doublet line of Ti $2 p$ for the NaTiNts was characterized by binding energy of $457.8 \mathrm{eV}\left(2 \mathrm{p}_{3 / 2}\right)$ with FWHM of $2.05 \mathrm{eV}$ and $464.3 \mathrm{eV}\left(2 \mathrm{p}_{1 / 2}\right)$ with FWHM of $2.60 \mathrm{eV}$ with a separation energy of $5.7 \mathrm{eV}$. The spectral lines of Ti $2 \mathrm{p}_{3 / 2}$ and Ti $2 \mathrm{p}_{1 / 2}$ are very similar to the reported values (Kim et al. 2007, Pótári et al. 2013). Ti $2 p$ double-stranded spectral lines for the HTiNts and AuTiNts present similar results, showing the 

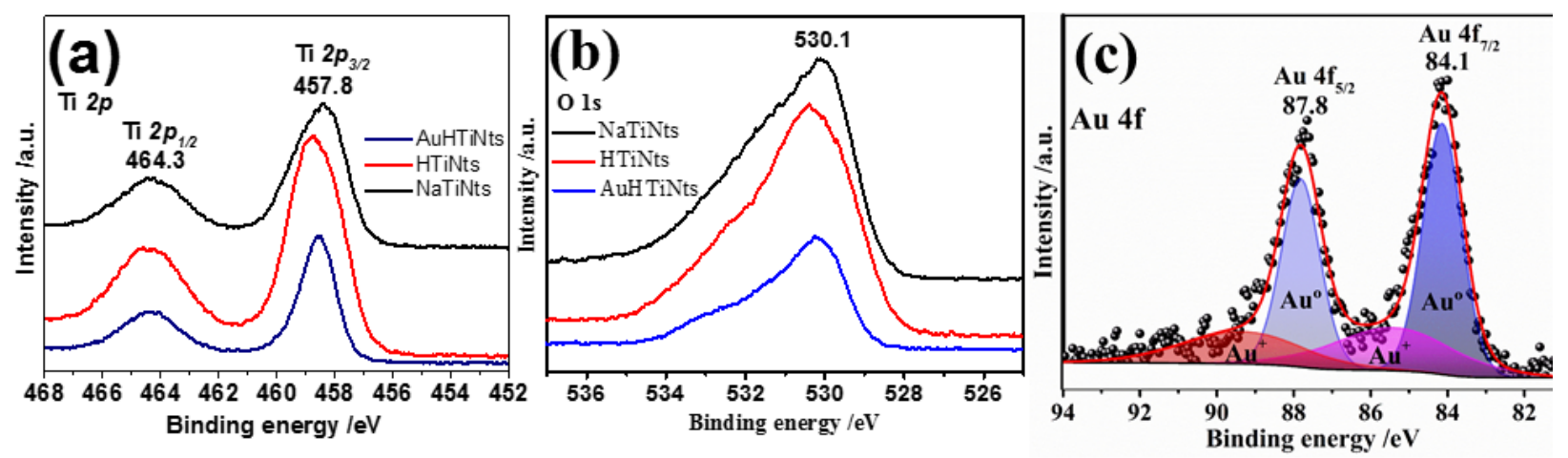

Figure 4 - High resolution XPS spectra of (a) Ti 2p, (b) O 1s signals for NaTiNts, HTiNts and AuHTiNts and (c) Au 4f signals for the AuHTiNts samples.

presence of $\mathrm{Ti}^{4+}$ (Deng et al. 2009, Kiss et al. 2014). The O 1s spectra for all the TiNts were shown in Fig. 4b. The O 1s spectra of NaTiNts can be deconvoluted in sub-peaks centered at 531.6, 530.3 and $529.1 \mathrm{eV}$, which can be assigned to the $\mathrm{H}_{2} \mathrm{O}$, OH and Ti-O, respectively (Fig. 5). Similar results were reported by Kim et al. where they discovered that the $\mathrm{O} 1 \mathrm{~s}$ peak is formed of $\mathrm{Ti}-\mathrm{O}$ in $\mathrm{TiO}_{2}$ and $\mathrm{OH}$ in Ti-OH (Kim et al. 2007).

The gold chemical environment in AuHTiNts was also investigated by XPS. The Au 4f spectra of AuHTiNts are displayed in Fig. 4c. The metallic $4 f_{7 / 2}$ and $4 f_{5 / 2}$ Au lines were observed at 84.1 and $87.8 \mathrm{eV}$, respectively, showing characteristic shoulders at higher energies due to the presence of $\mathrm{Au}^{+}$(Fig. 4c) (Kiss et al. 2012, Pusztai et al. 2014). The emergence of shoulder peaks at $4 \mathrm{f}_{7 / 2}(85.4 \mathrm{eV})$ and $4 \mathrm{f}_{5 / 2}(89.4 \mathrm{eV})$ indicates that $\mathrm{Au}$ deposition may have undergone through an ionic exchange process. The surface composition for all the samples was investigated by XPS (Table I), and in the case of AuHTiNts, the ratio of $\mathrm{Au}^{0} / \mathrm{Au}^{+}$was found to be 1.96, which indicates that approximately $66.22 \%$ of $\mathrm{Au}$ is in the reduced form $\left(\mathrm{Au}^{0}\right)$, decorating the external surfaces of the nanotubes external surface as AuNPs. The mixed oxidation state of $\mathrm{Au}$ found in this study appeared to be similar to the one that found in the literature (Kiss et al. 2014). This phenomenon can be explained as $\mathrm{Au}$ is partially stabilized on the titanate nanotubes in the form of
$\mathrm{Au}^{+}$by ionic exchange as well as in the form of the clusters of $\mathrm{Au}^{0}$. It is likely to occur in titanate nanotubes because they are well known as good ion exchanger (Kiss et al. 2012). The higher energy $(85.5 \mathrm{eV})$ band of $\mathrm{Au}^{+}$indicates that $\mathrm{Au}^{3+}$ was reduced to $\mathrm{Au}^{+}$which participates widely in ion exchange reaction with titanate nanotubes as $\mathrm{Au}^{+}$ represents a greater binding energy in the XPS in comparison with the state of the metallic gold (Tsai et al. 2009).

The UV-Vis diffuse reflectance spectroscopy were performed on HTiNts and AuHTiNts to obtain the optical spectra (Fig. 6) as well as the band gap values $\left(\mathrm{E}_{\text {gap }}\right)$ by extrapolating the straight section of the paraboloid curve obtained from the $\left[\mathrm{F}\left(\mathrm{R}_{\infty}\right) \mathrm{h} v\right]^{2}$ versus $\mathrm{E}_{\text {phot }}$ plot. The HTiNts showed $\mathrm{E}_{\text {gap }}$ equal to $3.30 \mathrm{eV}$, agreeing with the values reported by Ferreira et al. 2013 (Ferreira et al. 2013). However, when TiNts were decorated with AuNPs there was a slight decrease of $\mathrm{E}_{\text {gap }}$ to $3.28 \mathrm{eV}$, corroborating the results reported by Pusztai et al. (2014). The effect is related with the insertion of intermediate levels among the orbitals of the Valence band (O $2 p$ ) to the conduction band (Ti 3d) originated from AuNPs, thus facilitating the charge transport in the internal structures of the materials (Rouby et al. 2017). Studies carried out conclude that other metallic nanoparticles and sulfide, such as silver (Rodríguez-González et al. 2012) cadmium sulfide (Tang et al. 2013), cobalt (Ferreira et al. 2013) and 

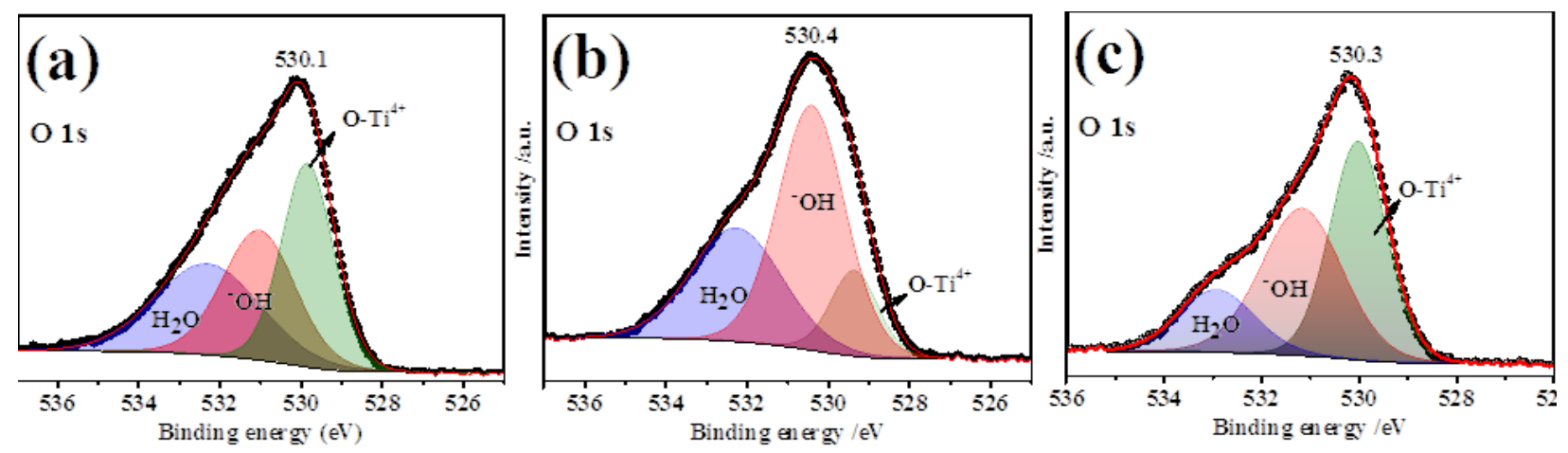

Figure 5 - High resolution XPS spectra of O 1s signals (a) of NaTiNts (b) HiTiNts and (c) AuHTiNts samples.

TABLE I

Surface composition of AuHTiNts and the percentage concentration of Au species.

\begin{tabular}{|c|c|c|c|c|c|c|c|}
\hline \multirow[b]{2}{*}{ Samples } & \multicolumn{5}{|c|}{ Surface composition } & \multicolumn{2}{|c|}{ \% Concentration of Au species } \\
\hline & $\mathrm{Na} 1 \mathrm{~s}$ & $\mathrm{O} 1 \mathrm{~s}$ & $\operatorname{Ti} 2 p$ & $\mathrm{Na} / \mathrm{Ti}$ & $\mathrm{Au} 4 \mathrm{f}$ & $\begin{array}{c}\mathrm{Au}^{\circ}(\mathrm{mol} \%) \\
{\left[4 \mathrm{f}_{7 / 2}: 84.1 \mathrm{eV}\right.} \\
\left.4 \mathrm{f}_{5 / 2}: 87.8 \mathrm{eV}\right]\end{array}$ & $\begin{array}{c}\mathrm{Au}^{+}(\mathrm{mol} \%) \\
{\left[4 \mathrm{f}_{7 / 2}: 85.5 \mathrm{eV}\right.} \\
\left.4 \mathrm{f}_{5 / 2}: 89.4 \mathrm{eV}\right]\end{array}$ \\
\hline NaTiNts & 7.25 & 79.85 & 11.48 & 0.63 & & - & - \\
\hline HTiNts & 0.66 & 80.90 & 21.29 & 0.03 & & - & - \\
\hline AuHTiNts & 0.69 & 76.91 & 21.60 & 0.03 & 0.80 & 66.22 & 33.78 \\
\hline
\end{tabular}

zinc (Vempati et al. 2015) show similar effect when NaTiNts and HTiNts surface after decoration with those nanoparticles.

Fig. 7 presents the irradiation results of glycerol as a sacrificial agent (glycerol/water solution $5 \% \mathrm{v} / \mathrm{v}$ ) on HTiNts and AuHTiNts samples. The photogeneration of $\mathrm{H}_{2}$ in the presence of AuHTiNts was strongly increased in comparison to HTiNts. The values obtained of $\mathrm{H}_{2}$ production was 853 $\mu \mathrm{mol} \mathrm{g}{ }^{-1}$ in $210 \mathrm{~min}$, a value considerably higher than the value showed using HTiNts, which was $121 \mu \mathrm{mol} \mathrm{g}{ }^{-1}$.

The Nanoparticles of $\mathrm{Au}<30 \mathrm{~nm}$, as observed in this work (Fig. 3), act as photon absorbers in the visible region of the spectrum as a consequence of the SPR effect (Fig.6). This phenomenon allows AuNPs to act as sensitizing agents, injecting hot electron into the titanate conduction band. On the other hand, the AuNPs also behave as local quantum dots concentrators of light, responsible for increasing the generation of electron-hole pairs that are induced by SPR onto semiconductor/liquid interface (Xinhua et al. 2017). The combination of these processes decreased the recombination of the excitons resulting in $600 \%$ increase of $\mathrm{H}_{2}$ production observed for AuHTiNts in compared to HTiNts.

The stability test of the AuHTiNts samples has been presented in Fig. 8. The experiment carried out in cycle 1 shows that the generation of $\mathrm{H}_{2}$ is not ceased immediately after the absence of light as observed by Jiang et al. (2008). Such phenomenon is observed due the adsorption of the photogenerated $\mathrm{H}_{2}$ onto outer or inner surface of the interlayers in nanotubes, which is released later, during the absence of light. However, in the presence of light the cycle 1 presented a significantly lower rate than that observed in the cycles 2, 3 and 4 (Table II). In the subsequent cycles 2, 3 and 4 the hydrogen generation rate stays steady, which show the excellent stability of the AuHTiNts since this material does not undergo process of photooxidation of the metal phase. 

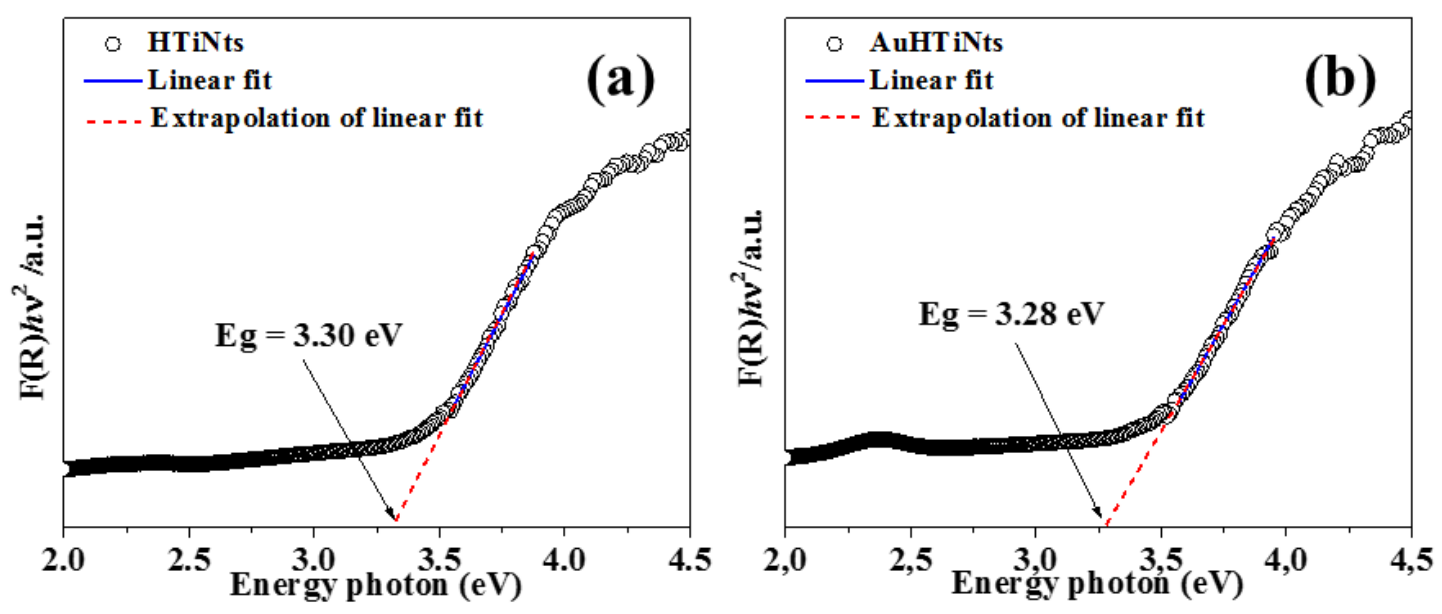

Figure 6 - Kubelka-Munk curves versus Photon energy $($ Ephot $=h v)$ of the (a) HTiNts and (b) AuHTiNts.

TABLE II

$\mathrm{H}_{2}$ evolution for AuHTiNts samples during multiple cycles.

\begin{tabular}{|c|c|c|c|c|}
\hline \multirow{2}{*}{ Cycle } & \multicolumn{2}{|c|}{ Quantity of $\mathrm{H}_{2}$ generated $(\mu \mathrm{mol} / \mathrm{g})$} & \multicolumn{2}{|c|}{ Rate of $\mathrm{H}_{2}$ production $(\mu \mathrm{mol} / \mathrm{g} / \mathrm{h})$} \\
\hline & After $5 h$ & Overnight & After $5 h$ & Overnight \\
\hline 2 & 966,54 & 1127,63 & 193,17 & 8,95 \\
\hline 3 & 952,18 & 1156,36 & 185,86 & 11,34 \\
\hline 4 & 1149,18 & 1125,58 & 206,43 & $-1,31$ \\
\hline
\end{tabular}

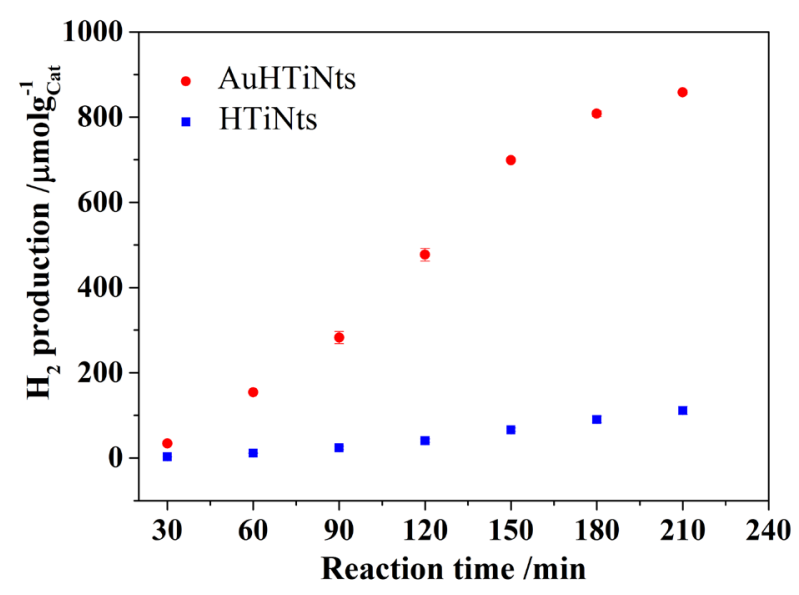

Figure 7 - Production of $\mathrm{H}_{2}$ from glycerol versus time of visible light exposure to $1.0 \%$ by weight of HTiNts (blue dots) and AuHTiNts (red dots).

In Table II the amount of $\mathrm{H}_{2}$ produced during the longer cycles as well as the rate of production are shown. For example, for cycle-2, $966.54 \mathrm{~mol}$ $\mathrm{H}_{2}$ was produced during 5 hours of irradiation with a production rate of $193.17 \mu \mathrm{mol} / \mathrm{g} / \mathrm{h}$. After the irradiation was stopped and the reactor was maintained closed in a dark chamber for 18 hours, it was found that more $161.09 \mu \mathrm{mol}$ of $\mathrm{H}_{2}$ was produced in dark during this 18 hours, which makes the overall rate ( 5 hours of irradiation +18 hours of darkness) changes to of $8.95 \mu \mathrm{mol} / \mathrm{g} / \mathrm{h} \mathrm{H}_{2}$ evolution.

It is worth mentioning that the rate of $\mathrm{H}_{2}$ generation during the cycles suggests that the process of glycerol photo-reform occurs slowly compared to the reduction reaction $\mathrm{H}^{+} \rightarrow \mathrm{H}_{2}$. This behavior is attributed to the absence of energetic holes, which are evidenced only in nanoparticles of $\mathrm{Au} \sim 2 \mathrm{~nm}$, unlike the hot electrons that are reported in SPR nanoparticles $<30 \mathrm{~nm}$ (Murdoch et al. 2011).

wAs expected, the deposition of AuNPs on to the nanotubes surface can facilitate the electrons capture, responsible for the reduction reaction giving rise to molecules of $\mathrm{H}_{2}$ (Fujishima et al. 2008, Murdoch et al. 2011). The presence of $\mathrm{Au}$ 


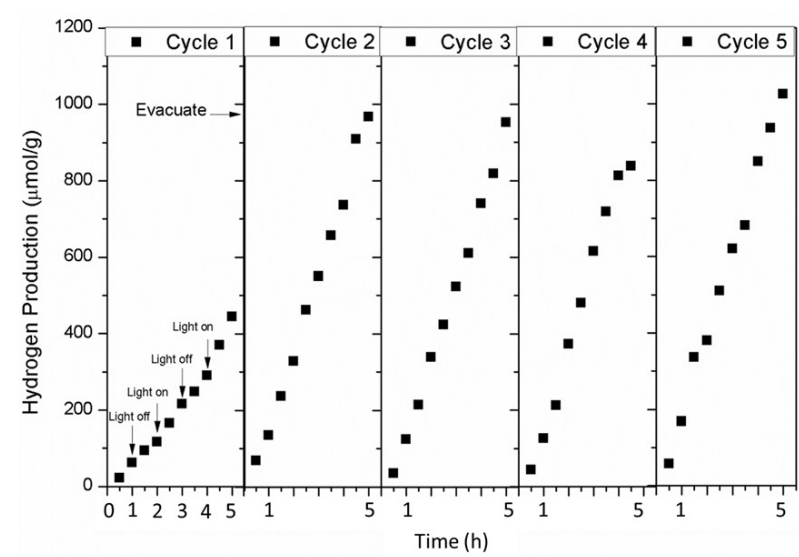

Figure $8-\mathrm{H}_{2}$ evolution by the catalyst AuHTiNts during five successive cycles.

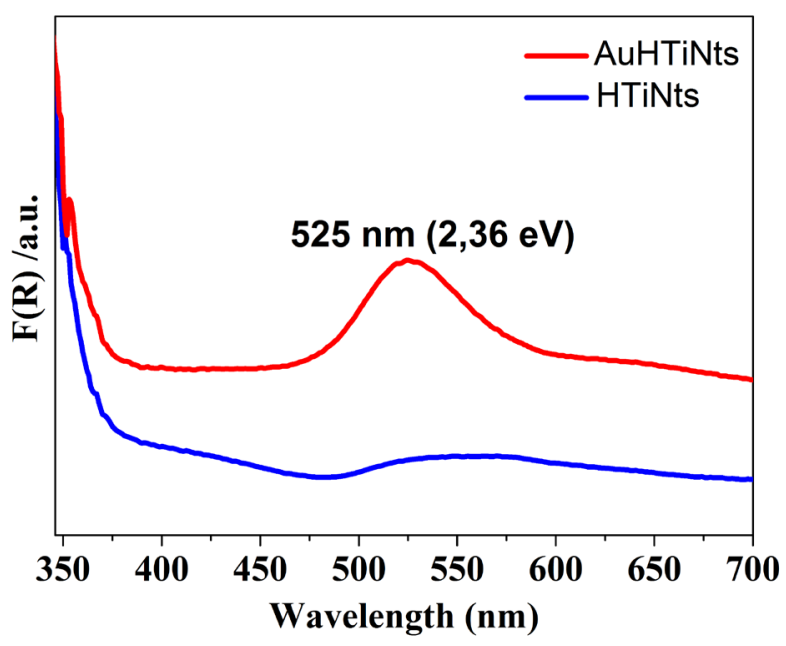

Figure 9 - Reflectance spectra for HTiNts (blue line) and AuHTiNts (red line). The broad band between 470 and 590 $\mathrm{nm}$ in AuHTiNts is associated with the Au structure supported on nanotubes.

particles promoted the emergence of absorption band in the visible range, with $\lambda_{\text {max }}=525 \mathrm{~nm}$, due to the SPR effect (Fig. 9), and the AuNPs can generate the charge dissipation in the nanotubes band conduction, improving the charge transfer (Panayotov et al. 2017).

\section{CONCLUSIONS}

AuHTiNts has been applied as photocatalysts to obtain hydrogen production at elevated rate using glycerol as a sacrificial agent. The photocatalysts were characterized by Raman spectroscopy, presenting typical vibrational modes of titanate nanotubes, which did not undergo major changes after AuNPs decoration. Furthermore, presence of anatase phase was confirmed. From XRD, it was observed that the crystalline structures and morphology of the titanate nanotubes were intact after the AuNPs formation. The TEM images exhibited homogeneous nanoparticles distribution on the surface nanotubes with an average size of $9.6 \mathrm{~nm}$. It was found by XPS that gold is stabilized in/on titanate nanotubes partially in the form of $\mathrm{Au}^{+}$ by ionic exchange and also as clusters of $\mathrm{Au}^{0}$ on the nanotubes surface. This elevated production of hydrogen, using the heterogeneous AuHTiNts catalysts, can be attributed to the intrinsic catalytic potential of gold and its interactions with titanate nanotubes.

\section{ACKNOWLEDGMENTS}

The authors acknowledge financial support from FAPEPI, FACEPE, Coordenação de Aperfeiçoamento de Pessoal de Nível Superior (CAPES) and Conselho Nacional de Desenvolvimento Científico e Tecnológico (CNPq), the technical support of Center for Strategic Technology of the Northeast (CETENE-PE) and Federal Institute of Education, Science and Technology of Piauí (IFPI), São João do Piauí PI. The authors declare that there is no conflict of interest regarding the publication of this paper.

\section{AUTHOR CONTRIBUTIONS}

The manuscript was written through the contribution of all authors, specifically: conceptualization, J.M.E.M., A.G., J.C.S.C. and B.C.V.; methodology, T.M.F.M., J.M.E.M., and J.C.S.C.; investigation, T.M.F.M., A.G., R.N.M, F.X.N, J.M.R., T.A.S.S., G.M., J.M.E.M. J.C.S.C. and B.C.V.; resources, J.M.E.M., J.C.S.C. and B.C.V.; supervision, J.M.E.M. and J.C.S.C.; project administration, T.M.F.M., J.M.E.M. and J.C.S.C.; funding 
acquisition, J.M.E.M. and J.C.S.C. All authors have given their approval to the final version of the manuscript.

\section{REFERENCES}

ABDULLAH M AND KAMARUDIN SK. 2017. Titanium dioxide nanotubes (TNT) in energy and environmental applications: An overview. Renew Sust Energ Rev 76: 212-225.

AHMAD H, KAMARUDIN SK, MINGGU LJ AND KASSIM M. 2015. Hydrogen from photo-catalytic water splitting process: A review. Renew Sust Energ Rev 43: 599-610.

BAMWENDA GR, TSUBOTA S, NAKAMURA T AND HARUTA M. 1995. Photoassisted hydrogen production from a water-ethanol solution: a comparison of activities of AuTiO2 and PtTiO2. J Photochem Photobiol A: Chem 89: 177-189.

BAVYKIN DV, FRIEDRICH JM AND WALSH FC.2006. Protonated titanates and $\mathrm{TiO} 2$ nanostructured materials: synthesis, properties, and applications. Adv Mater 18: 2807-2824.

BOWKER M, DAVIES PR AND AL-MAZROAI LS. 2009. Photocatalytic reforming of glycerol over gold and palladium as an alternative fuel source. Catal Letters 128: 253-253.

CAO SW, YIN Z, BARBER J, BOEY FYC, LOO SCJ AND XUE C. 2011. Preparation of Au-BiVO4 heterogeneous nanostructures as highly efficient visible-light photocatalysts. ACS Appl Mater Interfaces 4: 418-423.

CHEN Q, DU GH, ZHANG S AND PENG LM. 2002. The structure of trititanate nanotubes. Acta Crystallogr B 58: 587-593.

CRABTREE GW, DRESSELHAUS MS AND BUCHANAN MV. 2004. The hydrogen economy. Phys Today 57: 39-44.

CUSHING SK, LI J, BRIGHT J, YOST BT, ZHENG P, BRISTOW AD AND WU N. 2015. Controlling Plasmon-Induced Resonance Energy Transfer and Hot Electron Injection Processes in Metal@TiO2 Core-Shell Nanoparticles. J Phys Chem C 119: 16239-16244.

DASKALAKI VM AND KONDARIDES DI. 2009. Efficient production of hydrogen by photo-induced reforming of glycerol at ambient conditions. Catal Today 144(1-2): 7580.

DENG L, WANG S, LIU D, ZHU B, HUANG W, WU S AND ZHANG S. 2009. Synthesis, Characterization of Fe-doped TiO2 Nanotubes with High Photocatalytic Activity. Catal Lett 129: 513-518.

DE LA PISCINA PR AND HOMS N. 2008. Use of biofuels to produce hydrogen (reformation processes). Chem Soc Rev 37: 2459-2467.

DOSADO AG, CHEN WT, CHAN A, SUN-WATERHOUSE D AND WATERHOUSE GIN. 2015. Novel Au/TiO2 photocatalysts for hydrogen production in alcohol-water mixtures based on hydrogen titanate nanotube precursors. J Catal 330: 238-254.

DZUBIELLA J. 2010. Explicit and implicit modeling of nanobubbles in hydrophobic confinement. An Acad Bras Cienc 82: 3-12.

ESTAHBANATI MRK, FEILIZADEH M AND ILIUTA MC. 2017. Photocatalytic valorization of glycerol to hydrogen: Optimization of operating parameters by artificial neural network. Appl Catal B 209: 483-492.

ETACHERI V, VALENTIN CD, SCHNEIDER J, BAHNEMANN D AND PILLAI SC. 2015. Visible-light activation of $\mathrm{TiO} 2$ photocatalysts: Advances in theory and experiments. J Photochem Photobiol C 25: 1-29.

FANG W, XING M AND ZHANG J. 2017. Modifications on reduced titanium dioxide photocatalysts: A review. J Photochem Photobiol 32: 21-39.

FERREIRA OP, SOUZA FILHO AG, MENDES FILHO J AND ALVES OL. 2006. Unveiling the structure and composition of titanium oxide nanotubes through ion exchange chemical reactions and thermal decomposition processes. J Braz Chem Soc 17: 393-402.

FERREIRA VC, NUNES MR, SILVESTRE AJ AND MONTEIRO OC. 2013. Synthesis and properties of Codoped titanate nanotubes and their optical sensitization with methylene blue. Mater Chem Phys 142: 355-362.

FUJISHIMA A AND HONDA K. 1972. Electrochemical photolysis of water at a semiconductor electrode. Nature 238: 37-38.

FUJISHIMA A, ZHANG X AND TRYK DA. 2008. TiO2 photocatalysis and related surface phenomena. Surf Sci Rep 63: 515-582.

FUJITA SI, KAWAMORI H, HONDA D, YOSHIDA H AND ARAI M. 2016. Photocatalytic hydrogen production from aqueous glycerol solution using $\mathrm{NiO} / \mathrm{TiO} 2$ catalysts: Effects of preparation and reaction conditions. Appl Catal B Environ 181: 818-824.

GE MZ, CAO CY, HUANG JY, LI SH, ZHANG SN, DENG S, QING-SONG, ZHANG KQ AND LAI YK. 2016. Synthesis, modification, and photo/photoelectro- catalytic degradation applications of $\mathrm{TiO}_{2}$ nanotube arrays: a review. Nanotechnology 5: 1-38.

GE M, LI Q, CAO C, HUANG J, LI S, ZHANG S, CHEN Z, ZHANG K, AL-DEYAB SS AND LAI Y. 2017. Onedimensional $\mathrm{TiO}_{2}$ Nanotube Photocatalysts for Solar Water Splitting. Adv Sci 4: 1600152.

GUIMARÃES ZAS, DAMATTA RA, GUIMARÃES RS AND FILGUEIRA M. 2017. A Novel Porous Diamond Titanium Biomaterial: Structure, Microstructure, PhysicoMechanical Properties and Biocompatibility. An Acad Bras Cienc 89: 3111-3121.

INGRAM DB, CHRISTOPHER P, BAUER JL AND LINIC S. 2011. Predictive Model for the Design of Plasmonic 
Metal/Semiconductor Composite Photocatalysts. ACS

Catal 1: 1441-1447.

JAKOB M, LEVANON H AND KAMAT PV. 2003. Charge Distribution between UV-Irradiated TiO2 and Gold Nanoparticles: Determination of Shift in the Fermi Level. Nano Lett 3: 353-358.

JEDSUKONTORN T, UENO T, SAITO N AND HUNSOM M. 2018. Mechanistic aspect based on the role of reactive oxidizing species (ROS) in macroscopic level on the glycerol photooxidation over defected and defected-free TiO2. J. Photochem Photobiol A: Chemistry 367: 270-281.

JIANG J, GAO Q AND CHEN Z. 2008. Gold nanocatalysts supported on protonic titanate nanotubes and titania nanocrystals. J Mol Catal Chem 280: 233-239.

JOHN MR ST, FURGALA AJ AND SAMMELLS AF. 1983. Hydrogen generation by photocatalytic oxidation of glucose by platinized n-titania powder. J Phys Chem A 87: 801-805.

KIM GS, ANSARI SG, SEO HK, KIM YS AND SHIN HS. 2007. Effect of annealing temperature on structural and bonded states of titanate nanotube films. J Appl Phys 101: 24314.

KISS J, ÓVÁRI L, OSZKÓ A, PÓTÁRI G, TÓTH M, BAÁN K AND ERDÓHELYI A. 2012 Structure and reactivity of $\mathrm{Au}-\mathrm{Rh}$ bimetallic clusters on titanate nanowires, nanotubes and TiO2 (1 110$)$. Catal Today 181: 163-170.

KISS J, PUSZTAI P, ÓVÁRI L, BAÁN K, MERZA G, ERDÖHELYI A, KUKOVECZ A AND KÓNYA Z. 2014. Decoration of titanate nanowires and nanotubes by gold nanoparticles: XPS, HRTEM and XRD characterization. e-JSSNT 12: 252-258.

KUKOVECZ Á, KORDÁS K, KISS J AND KÓNYA Z. 2016. Atomic scale characterization and surface chemistry of metal modified titanate nanotubes and nanowires. Surf Sci Rep 71: 473-546.

LI R, KOBAYASHI H, TONG J, YAN X, TANG Y, ZOU S, JIN J, YI W AND FAN J. 2012. Radical-involved photosynthesis of AuCN oligomers from Au nanoparticles and acetonitrile. J Am Chem Soc 134: 18286-18294.

LI R, ZHU X, YAN X, SHOU D, ZHOU X AND CHEN W. 2016. Single component gold on protonated titanate nanotubes for surface-charge-mediated, additive-free dehydrogenation of formic acid into hydrogen. RSC Adv 6: 100103-100107.

LIU N, CHEN X, ZHANG J AND SCHWANK JW. 2014. A review on TiO2-based nanotubes synthesized via hydrothermal method: Formation mechanism, structure modification, and photocatalytic applications. Catal Today 225: 34-51.

MARQUES TMF, LUZ-LIMA C, SACILLOTI M, FUJISAWA K, PEREA-LOPEZ N, TERRONES M, SILVA EM, FERREIRA OP AND VIANA BC. 2017. Photoluminescence Enhancement of Titanate Nanotubes by Insertion of Rare Earth Ions in Their Interlayer Spaces. J Nanomater 2017: 1-9.

MARQUES TM, FERREIRA O, COSTA JDA, FUJISAWA K, TERRONES M AND CRUZ VIANA B. 2015. Study of the growth of $\mathrm{CeO} 2$ nanoparticles onto titanate nanotubes. J Phys Chem Solids 87: 213-220.

MCNUTT J AND YANG J. 2017. Utilization of the residual glycerol from biodiesel production for renewable energy generation. Renew Sust Energ Rev 71: 63-76.

MORGADO E, ABREU MAS, PRAVIAORC, MARINKOVIC BA, JARDIM PM, RIZZO FC AND ARAÚJO AS. 2006. A study on the structure and thermal stability of titanate nanotubes as a function of sodium content. Solid State Sci 8: $888-900$

MORGADO E, MARINKOVIC BA, JARDIM PM, ABREU MAS, ROCHA MGC AND BARGIELA P. 2011. Studies on Fe-modified nanostructured trititanates. Mater Chem Phys 126: 118-127.

MURDOCH M, WATERHOUSE GIN, NADEEM MA, METSON JB, KEANE MA, HOWE RF, LLORCA J AND IDRISS H. 2011. The effect of gold loading and particle size on photocatalytic hydrogen production from ethanol over $\mathrm{Au} / \mathrm{TiO} 2$ nanoparticles. Nat Chem 3: 489-492.

PANAYOTOV DA, FRENKEL AI AND MORRIS JR. 2017. Catalysis and photocatalysis by nanoscale $\mathrm{Au} / \mathrm{TiO} 2$ : Perspectives for renewable energy. ACS Energy Lett 2: 1223-1231.

PÓTÁRI G, MADARÁSZ D, NAGY L, LÁSZLÓ B, SÁPI A, OSZKÓ A, KUKOVECZ A, ERDOHELYI A, KÓNYA Z AND KISS J. 2013. Rh-induced support transformation phenomena in titanate nanowire and nanotube catalysts. Langmuir 29: 3061-3072.

PRIMO A, CORMA A AND GARCÍA H. 2011. Titania supported gold nanoparticles as photocatalyst. Phys Chem Chem Phys 13: 886-910.

PUSZTAI P, PUSKÁS R AND VARGA E. 2014. Influence of gold additives on the stability and phase transformation of titanate nanostructures. Phys Chem Chem Phys 16: 2678626797.

RODRÍGUEZ-GONZÁLEZ V, OBREGÓN-ALFARO S, LOZANO-SÁNCHEZ LM AND LEE SW. 2012. Rapid microwave-assisted synthesis of one-dimensional silverH2Ti3O7 nanotubes. J Mol Catal Chem 353: 163-170.

ROUBY WMA, COMESAÑA-HERMO M. TESTA-ANTA M, CARBÓ-ARGIBAY E, SALGUEIRIÑO V, PÉREZLORENZO M AND CORREA-DUARTE MA. 2017. Audecorated sodium titanate nanotubes as high-performance selective photocatalysts for pollutant degradation. 2017. J Phys D 50: 144002.

SAKTHIVEL S, SHANKAR MV, PALANICHAMY $\mathrm{M}$, ARABINDOO B, BAHNEMANN DW AND MURUGESAN V. 2004. Enhancement of photocatalytic activity by metal deposition: characterisation and photonic 
efficiency of $\mathrm{Pt}, \mathrm{Au}$ and $\mathrm{Pd}$ deposited on $\mathrm{TiO} 2$ catalyst. Water Res 38: 3001-3008.

SANWALD KE, BERTO TF, EISENREICH W, GUTIÉRREZ OY AND LERCHER JA. 2016. Catalytic routes and oxidation mechanisms in photoreforming of polyols. $\mathrm{J}$ Catal 344: 806-816.

TANG ZR, YIN X, ZHANG Y AND XU YJ. 2013. Synthesis of titanate nanotube-CdS nanocomposites with enhanced visible light photocatalytic activity. Inorg Chem 52: 11758-11766.

TSAI JY, CHAO JH AND LIN CH. 2009. Low temperature carbon monoxide oxidation over gold nanoparticles supported on sodium titanate nanotubes. J Mol Catal Chem 298: 115-124.

VALDÉS Á ET AL. 2012. Solar hydrogen production with semiconductor metal oxides: new directions in experiment and theory. Phys Chem Chem Phys 14: 49-70.

VEMPATI S, KAYACI-SENIRMAK F, OZGIT-AKGUN C, BIYIKLI N AND UYAR T. 2015. Surface ionic states and structure of titanate nanotubes. RSC Adv 5: 82977-82982.
VIANA BC, FERREIRA OP, FILHO AGS, HIDALGO AA, FILHO JM AND ALVES OL. 2011. Alkali metal intercalated titanate nanotubes: A vibrational spectroscopy study. Vib Spectrosc 55: 183-187.

WANG X, WANG W, MIAO Y, FENG G AND ZHANG R. 2016. Facet-selective photodeposition of gold nanoparticles on faceted $\mathrm{ZnO}$ crystals for visible light photocatalysis. J Colloid Interface Sci 475: 112-118.

XINHUA DU, YANG LI, HUI YIN AND QUANJUN X. 2017. Preparation of $\mathrm{Au} / \mathrm{TiO} 2 / \mathrm{MoS} 2$ Plasmonic Composite Photocatalysts with Enhanced Photocatalytic Hydrogen Generation Activity. Acta Phy-Chim Sin 34: 414-423.

YANG X, WU L, DU L AND LI X. 2015. Photocatalytic Water Splitting Towards Hydrogen Production on Gold Nanoparticles (NPs) Entrapped in TiO2 Nanotubes. Catal Lett 145: 1771-1777.

ZHU HY, LAN Y, GAO XP, RINGER SP, ZHENG ZF, SONG DY AND ZHAO JC. 2005. Phase transition between nanostructures of titanate and titanium dioxides via simple wet-chemical reactions. J Am Chem Soc 127: 6730-6736. 